\title{
Is It Better to Disclose or Conceal Medical Error When Occur? An Indicative Study from Sohag Governorate Physicians
}

\author{
Reda M. El Sayed ${ }^{1}$, Nesreen A. Mohammed ${ }^{2}$, Rania A. Radwan ${ }^{1}$ \\ ${ }^{1}$ Department of Forensic Medicine and Clinical Toxicology, Faculty of Medicine, Sohag University, Sohag, Egypt. \\ ${ }^{2}$ Department of Public Health and Community, Faculty of Medicine, Sohag University, Sohag, Egypt.
}

\begin{abstract}
Background:

Introduction: Medication errors as one of the commonest medical problems in hospitals are a leading cause of patient morbidity. Subjects and methods: three hundreds (300) doctors of different degrees were asked to fulfill the attached questionnaire about medical malpractice (causes, types, preventive measures) and their opinion about disclosure or concealing the errors. Results: The studied subjects included variable age groups, with range from 25 to 65 years old. The major cause of medical malpractice reported by the participants was deficient skills $45 \%$, followed by poor contact with patients (35\%). Other reported causes are due to stress and work overload (25\%). Twelve percent were due to poor team work arrangement. Only $23.7 \%$ of doctors decide to disclose their errors and $76.3 \%$ prefer to hide the medical errors. The most common error reported by participants was diagnosis errors (23.6\%), and then delayed transfer in $21 \%$. The outcome of patients secondary to error was minor in $72.6 \%$ and death occurred only in $4.67 \%$. The most reported suggested measure (51\%) for prevention of error recurrence was referral of difficult cases followed by performing risky procedures in qualified hospitals (42.6\%) and then to encourage doctors to disclose their error $41.3 \%$. Conclusion: The current study concluded that the main causes of medical errors were poor contact with patients and deficient skills. The most common mentioned errors were surgery in non-equipped place, unethical conduct and diagnosis error. The participants' response was avoiding similar situations and increase information to prevent recurrence. The majority of participating doctors chose concealing the errors to avoid loss of reputation Recommendations: Close monitoring of residents and adequate communication between staff and regularization of duty hours can decrease occurrence of errors. Legal protection for doctors and patients can encourage doctors to disclose their errors.
\end{abstract}

Key words Medical errors, disclosure of error, prevention of error

\section{Introduction}

I ncreased awareness of patients' rights, the development of medicine, and recent complicated 1 medical procedures lead to increasing the number of medical malpractice claims (Gündo gmus et al., 1998; Nakajima et al., 2001 and Martin-Casals et al., 2003).

Medical errors (MEs) as one of the most common types of medical problems in hospitals are a leading cause of patient morbidity. It is defined as "a failure in the treatment process which leads to, or may lead to, patient harm". Prevention of medication error can prevent many adverse incidents which negatively affect patients' safety, but due to insufficient poor studies plus wide variations in ME from developing countries, so the reliability of $\mathrm{ME}$ evaluation of is questionable (Ava et al., 2014).

There are many causes of medication errors. It may be related to professionalism, material, procedures, environment or regulations; may involve prescribing and ordering; dispensing and distribution; preparation and administration, packaging, and nomenclature; communications, or use and monitoring of treatment. (Wakefield et al., 2000)

There are many classifications for medical errors, one of them classify errors into three categories: serious, minor and near-miss. A serious error is one which can produce permanent or transient injuries that may be fatal in severe cases, while a minor error leads to harmful effects but are neither permanent nor life-threatening. Last type of error, a near-miss error that could produce harmful effects but did not produce it, due to either medical intervention and correction or it may be corrected accidentally by chance (Bari et al., 2016).

\section{Aim of the Work}

This work aimed to collect data from physicians among different specialties in Sohag governorate regarding:

1) The most important causes of medical errors and malpractice.

2) The opinion of physicians about disclosure or hiding of the error to patients. 
3) Types of medical errors they did if occurred, its outcome and how to prevent recurrence of the errors.

\section{Subjects and Methods}

Participants: The current study was conducted on three-hundred practicing physicians in Sohag governorate, Egypt, who accepted to participate in this study. Those physicians involved residents, specialists and consultants working in different specialties. Consent was obtained from all participating physicians before they filled in the questionnaire.

Data collection tool: The data was collected through a self-administered questionnaire (appendix-1). This questionnaire was used to assess the opinion of Sohag physicians about the cause of medical error, types and their response towards medical errors they did if occurred, and lastly whether disclosure is the best policy or hiding the error is better.

The questionnaire (Appendix-1) was categorized into five sections. Section A: made to describe demographic data of the participants, including the participants gender, age, specialty and position (degree). Section B: assessed the opinion of the participating physicians regarding causes of MEs. Section C: asked whether they had witnessed or had been part of a ME and the outcome. Section D: explored the attitudes and opinions of participants about disclosure of error in presence and in absence of risk to the patient. Finally, section E found out how to decrease or prevent MEs.

\section{Statistical analysis:}

All collected questionnaires were revised and data coded and organized for statistical analysis using IBM SPSS Statistics for Windows version 20. Qualitative data was expressed as number and percentage. Chisquare $\left(\chi^{2}\right)$ test was used for comparison of qualitative variables.

\section{Ethics considerations:}

Ethical approval for this study was obtained from the Medical Research Ethics Committee of Faculty of Medicine - Sohag University, according to the commitment standard operating procedure guidelines on 12/1/2021 under IRB Registration number: Soh-Med-21-01-13.

Appendix-1 Questionnaire: modified from (Yassa and Peter, 2018)

\begin{tabular}{|c|c|c|c|}
\hline \multicolumn{4}{|c|}{ Section A } \\
\hline & Name (optional): ............. & ........... & \\
\hline 1- Age (years): & $>35-45(\quad)$ & $>45-55(\quad)$ & $>55-65(\quad)$ \\
\hline 2- Gender: & Female ( ) & & \\
\hline 3- Degree: & General practitioner (resident) ( ) & Specialist ( ) & Consultant ( ) \\
\hline 4- Specialty: & Obstetrics/gynecology ( ) & Surgery ( ) & Anesthesia ( ) \\
\hline & Orthopedic surgery ( ) & Ophthalmology ( ) & Pediatric ( ) \\
\hline & Int. medicine ( ) Dermatology ( ) & Physiotherapy ( ) & Radiology ( ) \\
\hline
\end{tabular}

\section{In your opinion, why do doctors malpractice?}

Causes related to management system:

Work Overload ( )

Stress ( )

Poor communication between staff ( )

\section{Causes related to doctor}

Deficient skills ( )

Error in diagnosis and treatment ( )
Poor supervision ( )

\section{Section B}

Poor teamwork arrangement ( )

Bad equipment ( )

Poor contact with patients $($ )

Negligence ( )

\section{Type of error you did before if any:}

Unethical conduct ( )

Not indicated surgery ( )

Improper performance of surgical procedure ( )

Surgical foreign body/towel left in patient after

Inadequate postoperative follow-up( )

Improper supervision of resident or other

Your response:

Avoid similar situation ( )

Discuss with colleagues about this malpractice ( )

Report to supervision ( )

Outcome of the case after error occurrence:

minor ( ) moderate ( ) severe ( )

\section{Section C}

Delayed transfer ( )

Faulty anesthetic procedure ( )

Surgery in non-equipped place ( )

ration ( )

Improper treatment ( )

Increase information to decrease recurrence ( )

Bad emotional experience ( )

\section{Diagnosis errors ( )}


In presence of malpractice risk:

I will hide the error ( )

I will hide because

Litigation costs ( )

Loss of reputation ( )

Emotional impact of malpractice ( )

I will disclose because

Patient right to know what happened even if there is litigation risk ( )

Proper pre-treatment informed consent ( )

Increase patients confidence in doctors ( )

Late disclosure destroys doctor- patient relationship ( )

Part of effective reporting and learning ( ) Decrease litigation of error ( )

I want to be treated in similar way ( ) Decrease feeling of guilt ( )

How to prevent repetition of malpractice?

\section{Section D}

I will disclose ( )

Loss of doctor - patient relationship ( )

No training (how to disclose) ( )

Negative patient - family reaction ( )

\section{Administration related}

Perform risky procedures in big qualified hospitals ( )

Encourage hospitals to inform the agency by serious medical errors ( )

Encourage doctors to disclose ( )

\section{Human related}

Give physician more time to spend with patients ( ) Increase number of nurses ( )

Counting surgical items used during invasive procedure ( )

Refuse or referral of difficult case ( )

\section{Results}

The total number of participating physicians was 300 . Section (A) represented the demographic data. As regards the age and gender distribution of the participants it was outlined in table (1). Where 52.67\% of participants were males and $47.33 \%$ were females. the vast majority of participants were in age group 2535 years representing $42.33 \%$ followed by age group $>35-45$ years represented $35.67 \%$ then age group $>45$ 55 years represented $17 \%$, finally, age group $>55-65$ years represented $5 \%$.

For degree, most of them were specialists (62\%) followed by residents with percentage $23.67 \%$ and finally consultants (14.33\%) as shown in table (2). Different specialties shared in the study but most of them were internal medicine with percentage $28 \%$ followed by pediatrics (25.67\%) then obstetrics and gynecology (23.33\%), the other specialties shared with small percentages as shown in table (2).

Results of section (B) represented in table (3). It showed the causes of malpractice reported by participating doctors either due to management system or caused by doctors themselves which differs according to the degree of each doctor.

The consultants mentioned that the main cause is poor contact with patients with percentage (48.84\%) followed by deficient skills (27.91\%) then work overload and poor team work with equal percentage (25.58\%). Other causes reported were, poor communication with staff (20.93\%), followed by error in diagnosis and treatment (16.28\%), the remaining causes represented small percentage as bad equipment (9.3\%), stress and negligence have the same percentage (6.98\%), combined causes as work overload with stress have the same percentage (4.65\%) as poor supervision, the least cause mentioned was combination of work overload with poor team work arrangement (2.33\%).

The specialists have nearly the same opinions, as the main causes mentioned by them were poor contact with patients (44.62\%) and deficient skills (43.01\%), followed by stress (36.02\%) then work overload (24.73\%), poor team work arrangement (14.52\%), then combination of work overload with stress (12.9\%), the other causes represented small percentage as error in diagnosis and treatment (8.06\%), poor supervision (6.45\%) and negligence (4.3\%).

Finally, the residents reported that the main causes were deficient skills (61.97\%) followed by negligence (29.58), poor communication between staff and work overload nearly equal percent (26.76\%) and (25.35\%) respectively. Other causes have small percent poor teamwork arrangement (9.86\%), combined factors as (work overload and poor teamwork arrangement) represented $(8.45 \%)$, last causes reported were stress and error in diagnosis and treatment have the same percent $(7.04 \%)$.

Section (C) demonstrated types of errors reported by the participating doctors. The most common error mentioned by consultants was surgery in non-equipped place (30.23\%) followed by delayed transfer and improper treatment with equal percent (16.28\%) then improper supervision of residents and other staff (11.63\%), other types of errors occurred were unethical conduct, surgical foreign body left in patients, non-indicated surgery all with the same percent (6.98\%) and faulty anesthetic procedure has the smallest percent $(4.65 \%)$ as shown in figure (1).

Specialists mentioned the most common error occurred was unethical conduct (29.57\%) followed by delayed transfer (18.82\%) then diagnosis error 
(16.13\%), other types of errors were improper treatment (13.44\%), improper supervision of residents and staff members (10.75\%), faulty anesthetic procedure (5.38\%), inadequate postoperative follow up (4.84\%) lastly surgery in non-equipped place (1.08\%) as shown in figure (2).

Figure (3), showed types of errors reported by residents, from which diagnosis error represented the largest percent (57.74\%), followed by delayed transfer (29.58\%), then improper supervision of residents and staff members (8.45\%), lastly improper treatment (2.82\%) and unethical conduct (1.41\%).

Responses to the errors which occurred were different also according to the degree. Consultants response mainly was avoiding similar situation with a percent $51.16 \%$, followed by increase information to decrease recurrence (25.58\%), then discuss with colleagues about this malpractice (16.28\%) and lastly, bad emotional experience $(6.98 \%)$ as shown in figure (4).

Specialists have more or less similar response to errors as (49.5\%) of them stated that they will avoid similar situations in the future, followed by discuss with colleagues about this malpractice and increase information to decrease recurrence with percent (18.82\%) and (18.28\%) respectively then report to supervision (9.14\%) lastly, bad emotional experience (4.3\%) as shown in figure (5).

Residents have different response $(50.7 \%)$ of them reported that they increased information to decrease recurrence and (30.99\%) of them discussed with colleagues about this malpractice, (15.49\%) had bad emotional experience, (1.41\%) of them avoid similar situation, and reported to supervision as shown in figure (6).

Figure (7) showed the outcome of the affected patients. It differs from case to case, it was minor in (72.66\%) of patients, moderate $(16.67 \%)$, severe $(6 \%)$ and death occurred only in (4.67\%).

Section (D) described the reactions of doctors when malpractice occurred. Most of them, (76.23\%) decided that they will hide the medical errors if occurred and only (23.67\%) of them will disclose it to patients as shown in table (4).

Tables (5) and (6) showed the most common causes that make doctors hide or disclose medical errors, and why they hesitate to tell patients about the errors. Most of them (47.16\%) said that they conceal errors due to fear of loss of reputation, followed by $17.9 \%$ highlighted the emotional impact of malpractice, $10.48 \%$ to avoid loss of doctor - patient relationship, $9.17 \%$ fear of the negative reaction from patients' families, $8.3 \%$ fear of litigations cost, and lastly $6.99 \%$ not trained to disclose. Although most of physicians fear of disclosing errors, $23.67 \%$ decided to disclose. As $21.13 \%$ of them said that late disclosure destroys doctor- patient relationship and 18.31\% mentioned that it is the patient's right to know what happened even if there is litigation risk, while $16.9 \%$ reported that it will increase patient's confidence in doctors, $15.49 \%$ of them stated that they need to be treated in the same manner if the doctor becomes a patient. Fourteen percentages of them said that effective reporting and learning can make disclosure easy, $11.27 \%$ stated that proper informed consent should protect both the patients and doctors. Only $2.82 \%$ wanted to decrease feeling of guilt.

Last section (E) showed the suggested methods to prevent repetition of errors. As regards administrative preventive measures (42.7\%) of physicians said that performing risky procedures in big qualified hospitals will prevent recurrence of errors, nearly similar percent (41.3\%) will encourage doctors to disclose while (16\%) stated that it is better to encourage hospitals to inform the agency by serious medical errors.

Concerning human factors, $51.3 \%$ said that refuse or referral of difficult cases will save the patients and doctors, $34.3 \%$ need to give physician more time to spend with patients, $12.3 \%$ stated that increase number of nurses and assistant staff will decrease the occurrence of errors, only $2 \%$ said that counting surgical items used during invasive procedure will prevent recurrence of errors.

Table (1): The relation between age, gender, and degree of the participating physicians (No.=300).

\begin{tabular}{|c|c|c|c|c|c|c|c|c|}
\hline \multirow{3}{*}{ Characteristics } & \multicolumn{6}{|c|}{ Degree } & \multirow{2}{*}{\multicolumn{2}{|c|}{$\begin{array}{c}\text { Total } \\
\text { (No.=300) }\end{array}$}} \\
\hline & \multicolumn{2}{|c|}{$\begin{array}{l}\text { Consultant } \\
\text { (No. }=43 \text { ) }\end{array}$} & \multicolumn{2}{|c|}{ Resident (No.=71) } & \multicolumn{2}{|c|}{$\begin{array}{l}\text { Specialist } \\
\text { (No.=186) }\end{array}$} & & \\
\hline & No. & $\%$ & No. & $\%$ & No. & $\%$ & No. & $\%$ \\
\hline Age (year) & & & & & & & & \\
\hline $25-35$ & 0 & 0 & 70 & 98.59 & 57 & 30.65 & 127 & 42.33 \\
\hline$>35-45$ & 5 & 11.63 & 1 & 1.41 & 101 & 54.3 & 107 & 35.67 \\
\hline$>45-55$ & 23 & 53.49 & 0 & 0 & 28 & 15.05 & 51 & 17 \\
\hline$>55-65$ & 15 & 34.88 & 0 & 0 & 0 & 0 & 15 & 5 \\
\hline Gender & & & & & & & & \\
\hline Female & 6 & 13.95 & 46 & 64.79 & 90 & 48.39 & 142 & 47.33 \\
\hline Male & 37 & 86.05 & 25 & 35.21 & 96 & 51.6 & 158 & 52.67 \\
\hline
\end{tabular}


Table (2): Distribution of the participating physicians according to degree and specialty (No.=300).

\begin{tabular}{|c|c|c|}
\hline Characteristics & Number & Percentage \% \\
\hline Degree & & 14.33 \\
Consultant & 43 & 62 \\
Specialist & 186 & 23.67 \\
Resident & 71 & 3.67 \\
Specialty & 11 & 3.67 \\
Anesthesia & 11 & 28 \\
Dermatology & 84 & 23.33 \\
Int. medicine & 70 & 1 \\
Obstetrics/gynecology & 3 & 6 \\
Ophthalmology & 18 & 25.67 \\
Orthopedic surgery & 77 & 8.67 \\
Pediatric & 26 & \\
Surgery &
\end{tabular}

Table (3): The relation between the perceived causes of doctors' malpractices and degree by using Chi-Square test (No.= 300).

\begin{tabular}{|c|c|c|c|c|c|c|c|c|c|}
\hline \multirow{3}{*}{ Causes } & \multicolumn{6}{|c|}{ Degree } & \multirow{2}{*}{\multicolumn{2}{|c|}{$\begin{array}{c}\text { Total } \\
\text { (No.=300) }\end{array}$}} & \multirow{3}{*}{$\begin{array}{c}P- \\
\text { value }\end{array}$} \\
\hline & \multicolumn{2}{|c|}{$\begin{array}{c}\text { Consultant } \\
(\text { No. }=43)\end{array}$} & \multicolumn{2}{|c|}{$\begin{array}{l}\text { Resident } \\
\text { (No.=71) }\end{array}$} & \multicolumn{2}{|c|}{$\begin{array}{l}\text { Specialist } \\
(\text { No.=186) }\end{array}$} & & & \\
\hline & No. & $\%$ & No. & $\%$ & No. & $\%$ & No. & $\%$ & \\
\hline $\begin{array}{c}\text { Causes related to management. } \\
\text { Bad equipment } \\
\text { Poor com. between staff } \\
\text { Poor supervision } \\
\text { Poor teamwork arrangement. } \\
\text { Stress } \\
\text { Work Overload } \\
\text { Work Overload, Poor teamwork } \\
\text { arrangement } \\
\text { Work Overload, Stress }\end{array}$ & $\begin{array}{c}4 \\
9 \\
2 \\
11 \\
3 \\
11 \\
1 \\
2\end{array}$ & $\begin{array}{c}9.30 \\
20.93 \\
4.65 \\
25.58 \\
6.98 \\
25.58 \\
2.33 \\
\\
4.65\end{array}$ & $\begin{array}{c}3 \\
19 \\
3 \\
7 \\
5 \\
18 \\
6\end{array}$ & $\begin{array}{c}4.23 \\
26.76 \\
4.23 \\
9.86 \\
7.04 \\
25.35 \\
8.45 \\
\\
14.08\end{array}$ & $\begin{array}{c}4 \\
2 \\
12 \\
27 \\
67 \\
46 \\
4\end{array}$ & $\begin{array}{c}2.15 \\
1.08 \\
6.45 \\
14.52 \\
36.02 \\
24.73 \\
2.15 \\
\\
12.90\end{array}$ & $\begin{array}{l}11 \\
30 \\
17 \\
45 \\
75 \\
75 \\
11 \\
\end{array}$ & $\begin{array}{c}3.67 \\
10 \\
5.67 \\
15 \\
25 \\
25 \\
3.67 \\
\\
12\end{array}$ & $<0.001$ \\
\hline $\begin{array}{c}\text { Causes related to doctor. } \\
\text { Deficient skills } \\
\text { Error in diagnosis and treatment. } \\
\text { Negligence } \\
\text { Poor contact with patients }\end{array}$ & $\begin{array}{c}12 \\
7 \\
3 \\
21\end{array}$ & $\begin{array}{c}27.91 \\
16.28 \\
6.98 \\
48.84\end{array}$ & $\begin{array}{c}44 \\
5 \\
21 \\
1\end{array}$ & $\begin{array}{c}61.97 \\
7.04 \\
29.58 \\
1.41\end{array}$ & $\begin{array}{c}80 \\
15 \\
8 \\
83\end{array}$ & $\begin{array}{c}43.01 \\
8.06 \\
4.3 \\
44.62\end{array}$ & $\begin{array}{c}136 \\
27 \\
32 \\
105\end{array}$ & $\begin{array}{c}45.33 \\
9 \\
10.67 \\
35\end{array}$ & $<0.001$ \\
\hline
\end{tabular}

$P$-value was calculated by Chi-Square Test, $P$-value $<0.05$ is statistically significant

Table (4): The relation between the reaction of the doctors towards medical errors did before and the degree by using Chi-Square test

\begin{tabular}{|c|c|c|c|c|c|c|c|c|c|}
\hline \multirow{3}{*}{ Characteristics } & \multicolumn{6}{|c|}{ Degree } & \multirow{2}{*}{\multicolumn{2}{|c|}{$\begin{array}{c}\text { Total } \\
(\text { No. }=300)\end{array}$}} & \multirow{3}{*}{$\begin{array}{c}\text { P- } \\
\text { value }\end{array}$} \\
\hline & \multicolumn{2}{|c|}{$\begin{array}{c}\text { Consultant } \\
\text { (No.=43) }\end{array}$} & \multicolumn{2}{|c|}{$\begin{array}{l}\text { Resident } \\
(\text { No.=71) }\end{array}$} & \multicolumn{2}{|c|}{$\begin{array}{l}\text { Specialist } \\
\text { (No.=186) }\end{array}$} & & & \\
\hline & No. & $\%$ & No. & $\%$ & No. & $\%$ & No. & $\%$ & \\
\hline $\begin{array}{l}\text { Response when malpractice occurred } \\
\text { I will disclose } \\
\text { I will hide the error }\end{array}$ & $\begin{array}{l}17 \\
26\end{array}$ & $\begin{array}{l}39.53 \\
60.47\end{array}$ & $\begin{array}{l}12 \\
59\end{array}$ & $\begin{array}{l}16.9 \\
83.1\end{array}$ & $\begin{array}{c}42 \\
144\end{array}$ & $\begin{array}{l}22.58 \\
77.42\end{array}$ & $\begin{array}{c}71 \\
229\end{array}$ & $\begin{array}{l}23.67 \\
76.33\end{array}$ & 0.019 \\
\hline
\end{tabular}

P-value was calculated by Chi-Square Test, $P$-value $<0.05$ is statistically significant 
Table (5): The relation between causes of concealing (hiding) and the degree by using Chi-Square test (No.=229).

\begin{tabular}{|c|c|c|c|c|c|c|c|c|c|}
\hline \multirow{3}{*}{$\begin{array}{l}\text { In presence of malpractice risk, } \\
\text { causes of concealing }\end{array}$} & \multicolumn{6}{|c|}{ Degree } & \multirow{2}{*}{\multicolumn{2}{|c|}{$\begin{array}{c}\text { Total } \\
\text { (No.= 229) }\end{array}$}} & \multirow{3}{*}{$\begin{array}{c}\text { P- } \\
\text { value }\end{array}$} \\
\hline & \multicolumn{2}{|r|}{$\begin{array}{l}\text { Consultant } \\
\text { (No.=26) }\end{array}$} & \multicolumn{2}{|r|}{$\begin{array}{l}\text { Resident } \\
(\text { No. }=59)\end{array}$} & \multicolumn{2}{|c|}{$\begin{array}{l}\text { Specialist } \\
(\text { No. }=144)\end{array}$} & & & \\
\hline & No. & $\%$ & No. & $\%$ & No. & $\%$ & No. & $\%$ & \\
\hline Emotional impact of malpractice & 0 & & 32 & & 9 & 6.25 & 41 & 17.90 & \\
\hline Litig & 8 & 0.0 & 6 & & 5 & 3.47 & 19 & 8.30 & \\
\hline Loss of doctor - patient relationship & 2 & 30.77 & 2 & 2410.173 .39 & 20 & 13.89 & 24 & 10.48 & 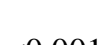 \\
\hline Loss of reputation & 5 & 7.69 & 11 & 3.645 .08 & 92 & 63.89 & 108 & 47.16 & $<0.001$ \\
\hline Negative patient family reaction & 3 & 19.2311.5430.77 & 3 & & 15 & 10.42 & 21 & 9.17 & \\
\hline No training (how to disclose) & 8 & & 5 & & 3 & 2.08 & 16 & 6.99 & \\
\hline
\end{tabular}

$P$-value was calculated by Chi-Square Test, $P$ - value $<0.05$ is statistically significant

Table (6): The relation between causes of disclosing malpractice and the degree by using Chi-Square test (No.=71).

\begin{tabular}{|c|c|c|c|c|c|c|c|c|c|}
\hline \multirow{3}{*}{ Causes of disclosing malpractice } & \multicolumn{6}{|c|}{ Degree } & \multirow{2}{*}{\multicolumn{2}{|c|}{$\begin{array}{c}\text { Total } \\
(\text { No. }=71)\end{array}$}} & \multirow{3}{*}{$\begin{array}{c}\text { P- } \\
\text { value }\end{array}$} \\
\hline & \multicolumn{2}{|c|}{$\begin{array}{c}\text { Consultant } \\
\text { (No.=17) }\end{array}$} & \multicolumn{2}{|c|}{$\begin{array}{l}\text { Resident } \\
(\text { No.=12) }\end{array}$} & \multicolumn{2}{|c|}{$\begin{array}{c}\text { Specialist } \\
(\text { No. }=42)\end{array}$} & & & \\
\hline & No. & $\%$ & No. & $\%$ & No. & $\%$ & No. & $\%$ & \\
\hline Decrease feeling of guilt & 0 & 0.0 & 0 & 0.0 & 2 & 4.76 & 2 & 2.82 & \\
\hline I want to be treated in similar way & 4 & 23.53 & 1 & 8.33 & 6 & 14.29 & 11 & 15.49 & \\
\hline Increase patients confidence in doctors & 3 & 17.65 & 1 & 8.33 & 8 & 19.05 & 12 & 16.90 & \\
\hline Late disclosure destroys doctor- patient relationship & 6 & 35.29 & 0 & 0.0 & 9 & 21.43 & 15 & 21.13 & 0.013 \\
\hline Part of effective reporting and learning & 1 & 5.88 & 6 & 50 & 3 & 7.14 & 10 & 14.08 & \\
\hline Patient right to know what happened even if there is an error & 0 & 0.0 & 3 & 25 & 10 & 23.81 & 13 & 18.31 & \\
\hline Proper pre-treatment informed consent & 3 & 17.65 & 1 & 8.33 & 4 & 9.52 & 8 & 11.27 & \\
\hline
\end{tabular}

$P$-value was calculated by Chi-Square Test, $P$ - value $<0.05$ is statistically significant

Table (7): The suggested measures for prevention of malpractice repetition

\begin{tabular}{|c|c|c|}
\hline The suggested measures & \multicolumn{2}{|c|}{ Total } \\
(No.=300) \\
\cline { 2 - 3 } Administration Related & No. & \% \\
Encourage doctors to disclose & 124 & 41.33 \\
Encourage hospitals to inform the agency by serious medical errors & 48 & 16 \\
Perform risky procedures in big qualified hospitals & 128 & 42.67 \\
\hline Human Related & 6 & 2 \\
Counting surgical items used during invasive procedure & 103 & 34.33 \\
Give physician more time to spend with patients & 37 & 12.33 \\
Increase number of nurses & 154 & 51.33 \\
\hline Refuse or referral of difficult case & & \\
\hline
\end{tabular}




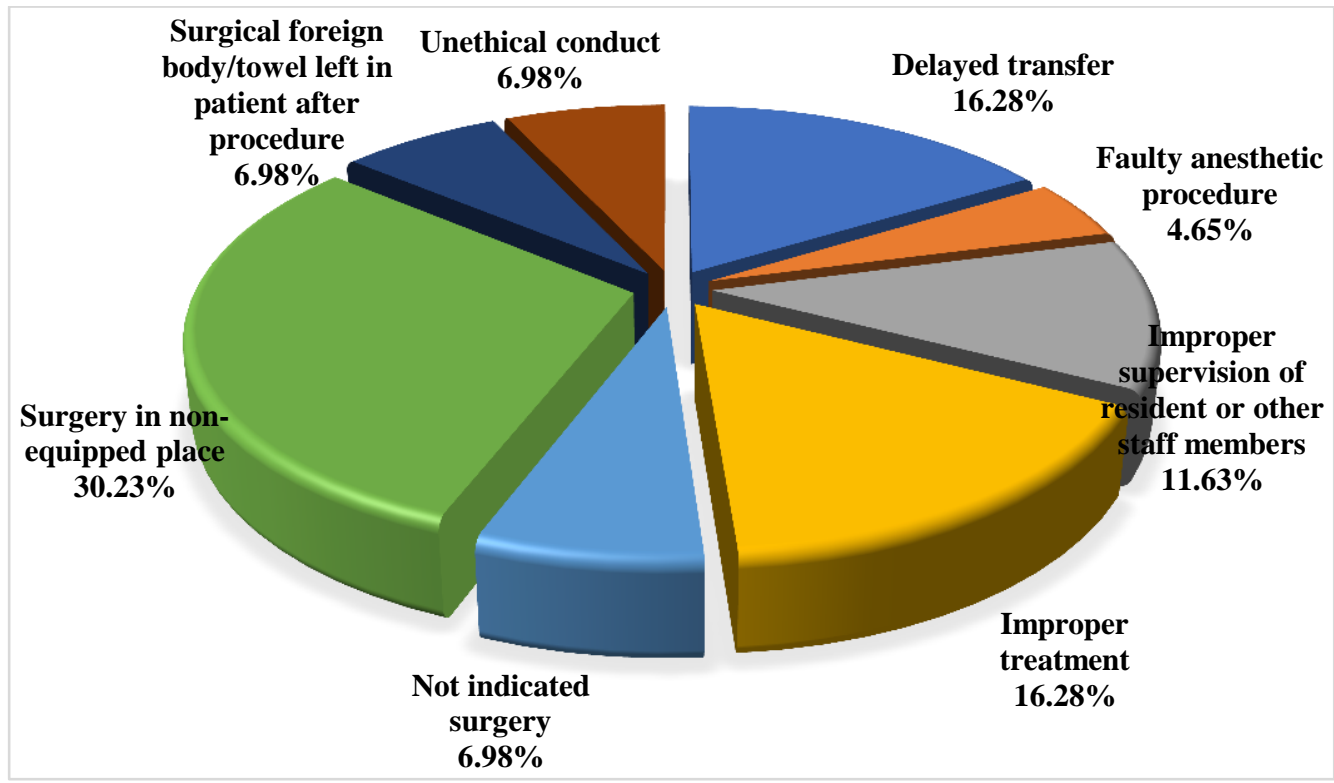

Figure (1): Types of medical errors reported by consultants (No.=43).

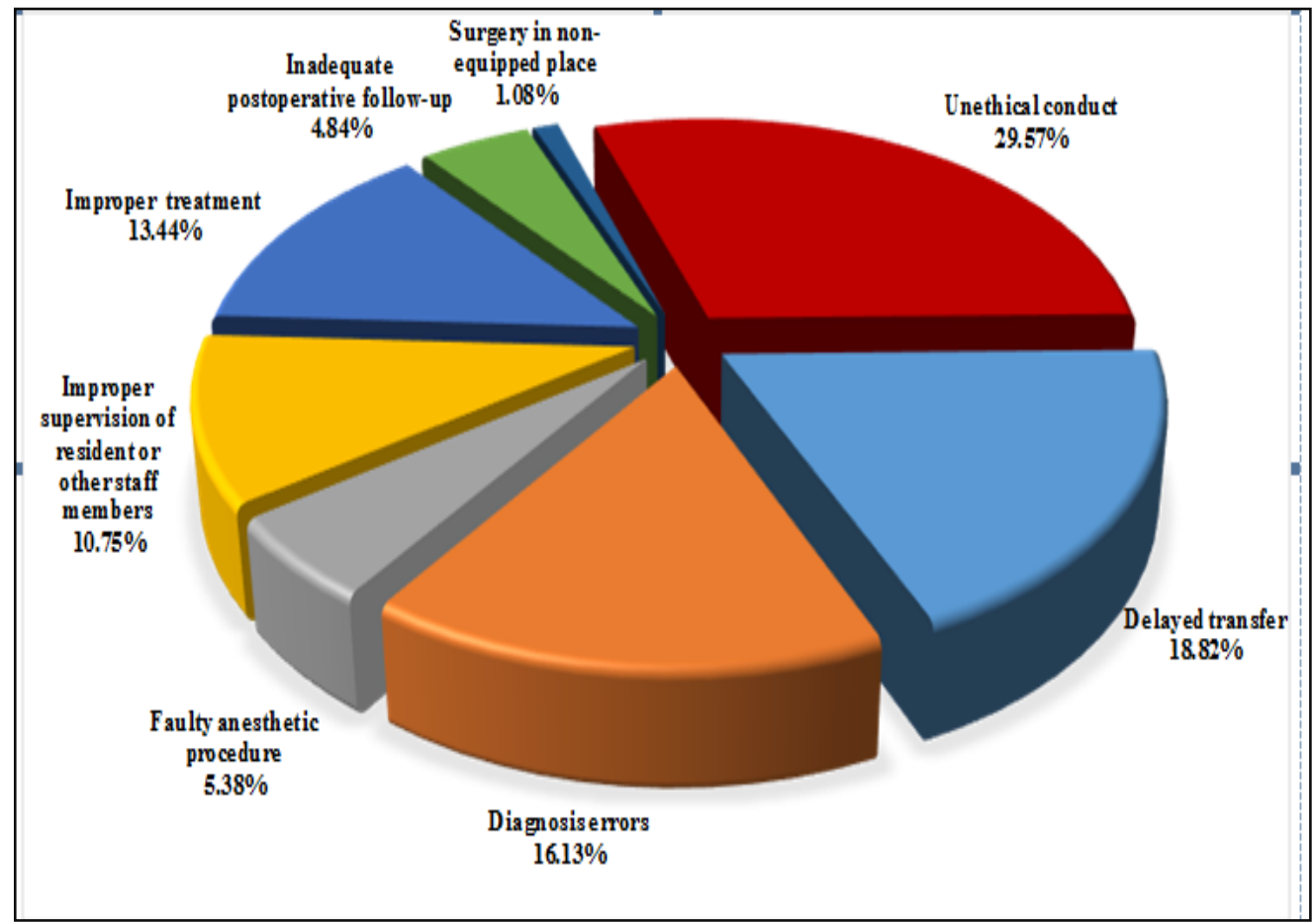

Figure (2): Types of medical error reported by specialists (No.=186) 


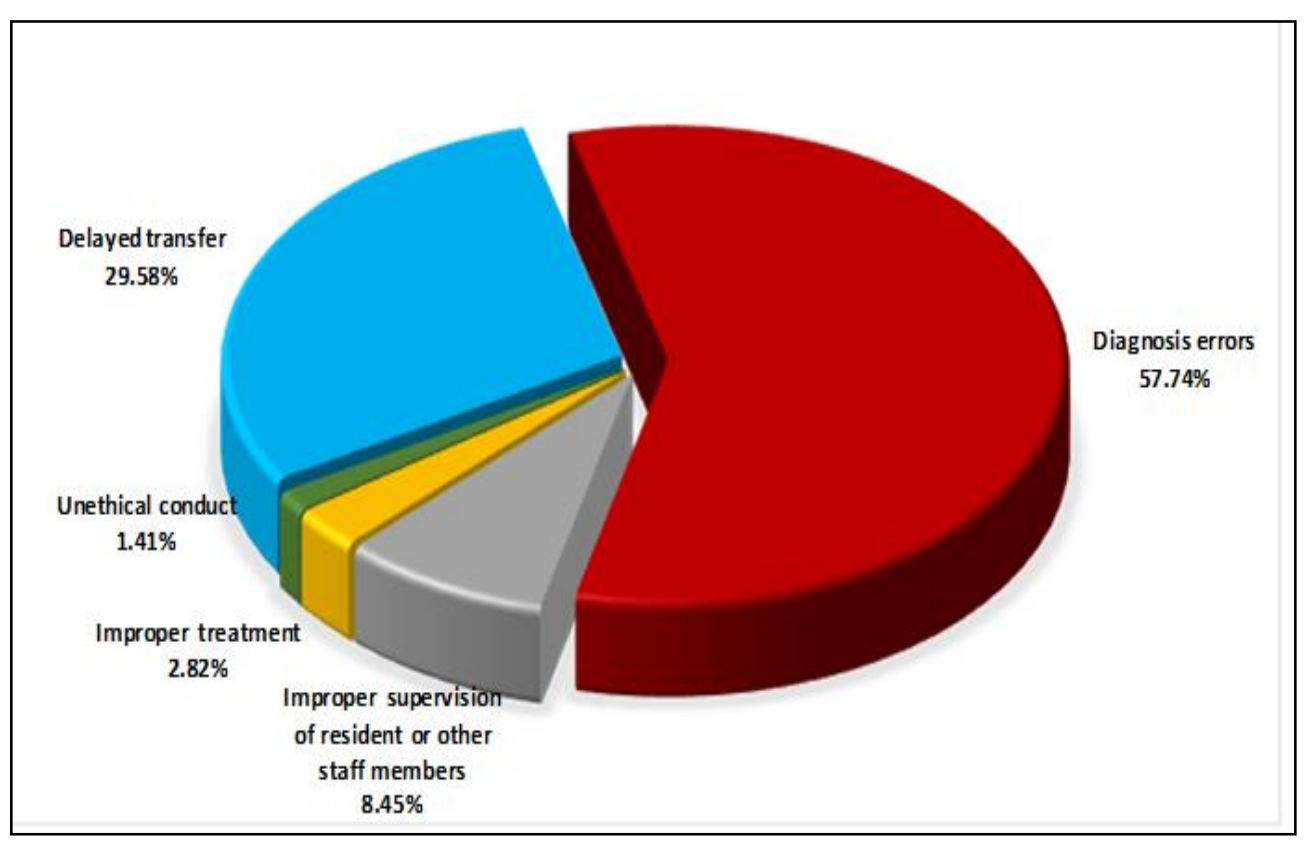

Figure (3): Types of medical error reported by residents (No. 71)

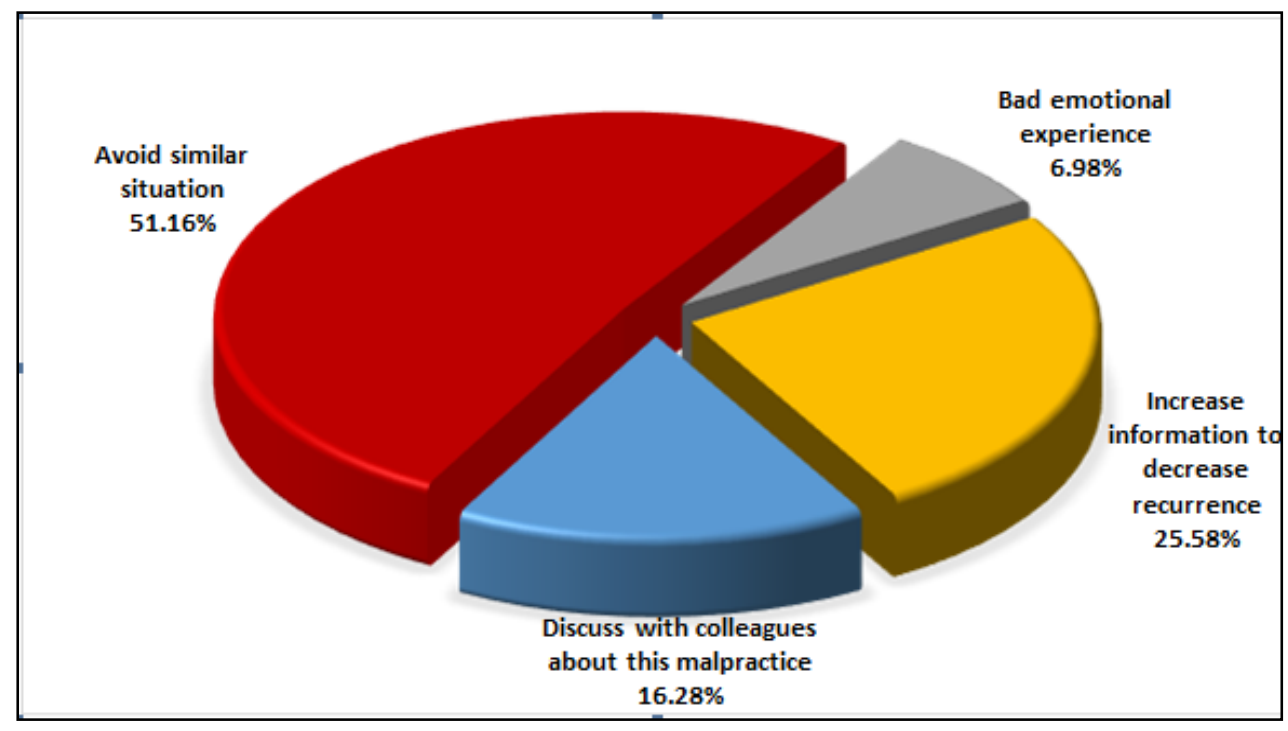

Figure (4): The response of consultants to medical errors they did before (No.=43). 


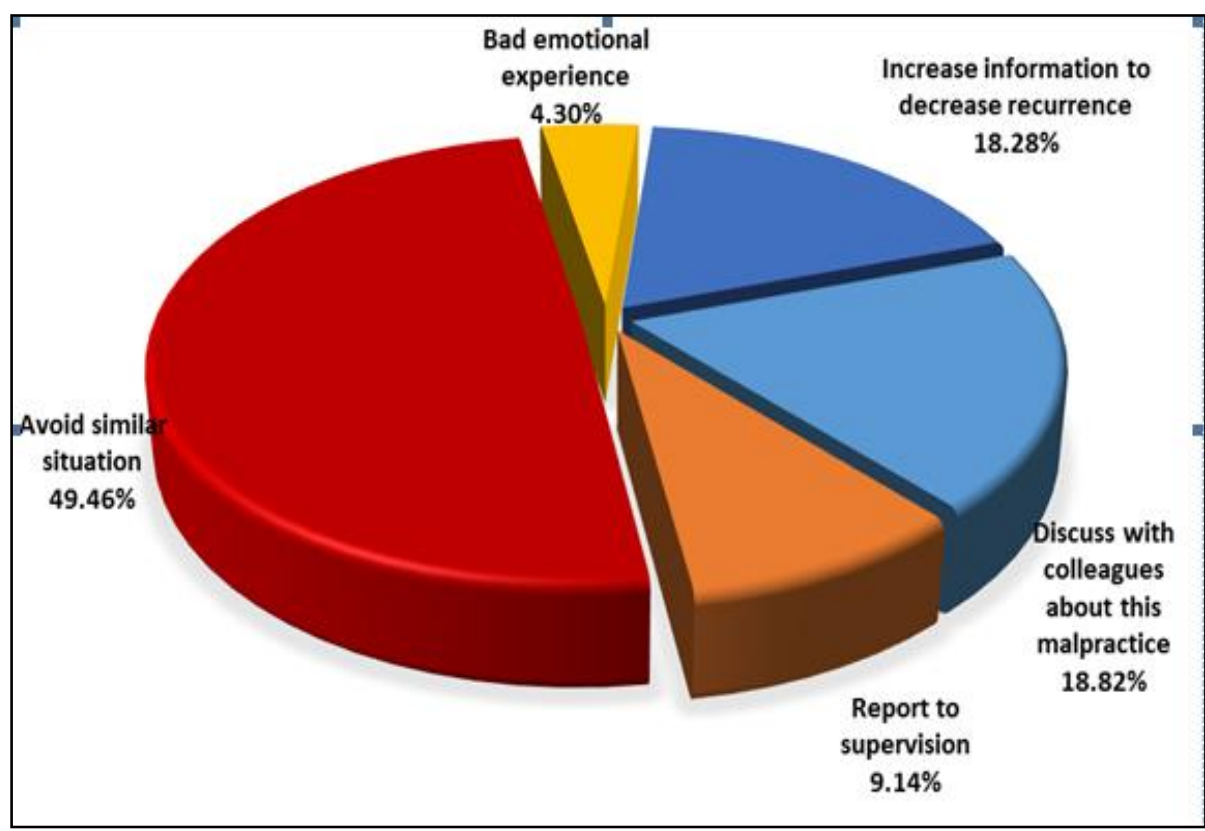

Figure (5): The response of specialists to medical errors they did before (No.=186).

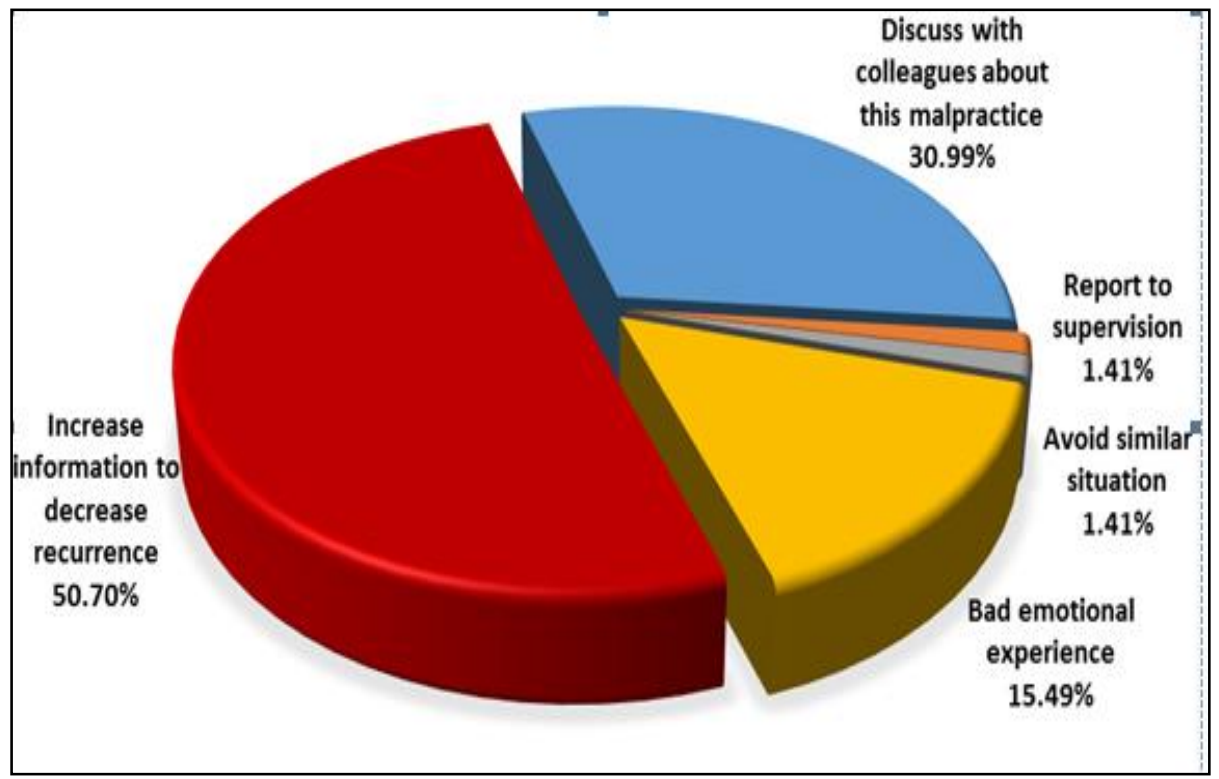

Figure (6): The response of residents to medical errors they did before (No.=71).

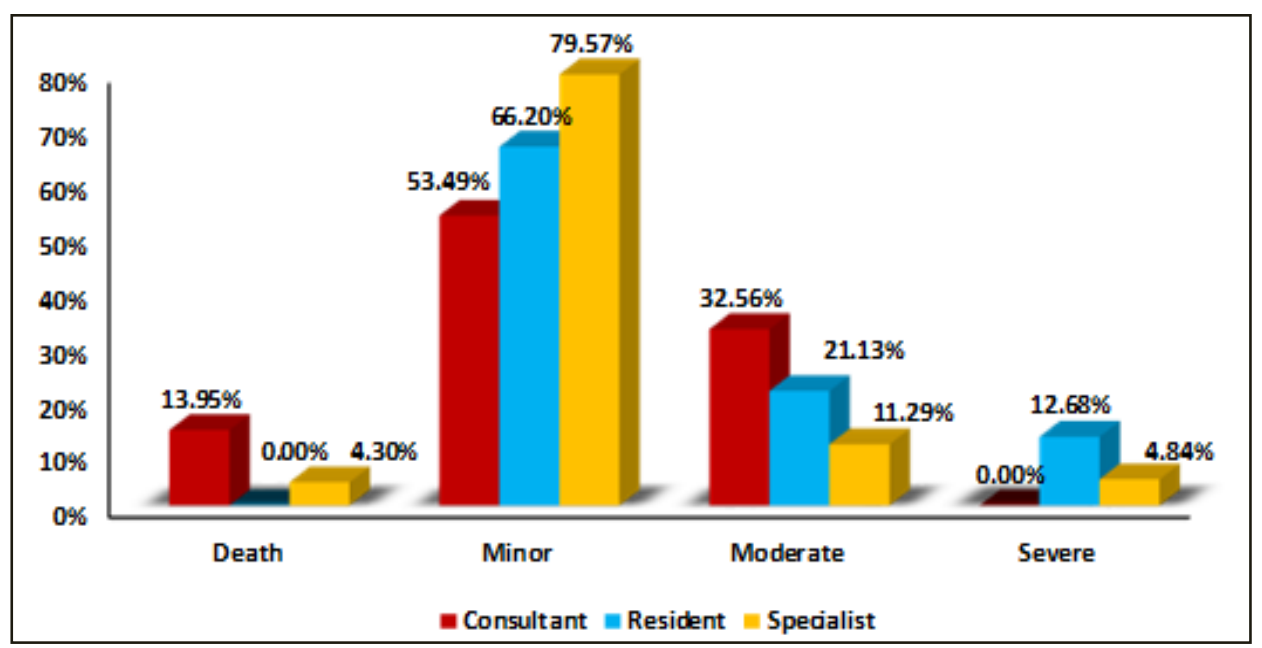

Figure (7): The relation between the outcome of errors and the degree (No.=300). 


\section{Discussion}

There is a continuous controversy between the right of patients to know and the right of doctors to conceal the medical errors to avoid loss of their reputation or malpractice litigations. The current study was conducted to detect the most important causes of medical errors and malpractice. The opinion of Sohag physicians about disclosure or hiding of the error to patients. Types of medical errors they did if any, its outcome and how to prevent recurrence of the errors. This study covered 300 physicians from Sohag Governorate. Their age ranged from 25 to 65 years old. It covered different specialties in different branches of medicine and surgery. Different degrees shared in this study from resident to consultant. According to the opinion of participating physicians (consultants and specialists), the most common cause of malpractice in human factors was due to poor contact with patients then deficient skills while residents reported that the main cause is deficient skills then negligence. These results are in agreement with Brennan et al. (2004), in their study about incidence of deleterious proceedings and negligence in patients, they found that $27.6 \%$ of these proceedings were due to negligence. While West et al. (2009) stated that medical errors are common in residents and this is often associated with personal distress.

The present results are in harmony with Binny et al. (2019), results who reported that medication errors were attributed to multifactor. These factors either active failures as mistakes followed by error-provoking conditions as deficient information and experience, inadequate staffing, with latent failures (e.g. heavy workload) were least mentioned.

For the management system causes both stress and work overload were the main factors for (consultants and specialists) while residents reported that the main causes were poor communication between staff and work overload. These results differ from the study of Yassa and Peter (2018), which was performed in Assiut Governorate, who reported that the most common cause of malpractice (31\%) was due to overwork, followed by stress in $27 \%$, and $18 \%$ due to poor team design. Rare causes were due to poor goals (3\%) such as overbilling, followed by poor equipment $(5 \%)$ and lack of supervision. In addition, 49\% were due to miscommunication with patients followed by $33 \%$ due to negligence.. Also, Tully et al. (2009), mentioned that the active failure which most frequently recorded was an error due to deficient information about the medications or the patient. There were matters of deficient training or experience, exhaustion, stress, work overload and poor contact between staff members

It is a vicious circle: stress upon physicians and decreased sympathy will lead to increased risk of medical errors in the future.

Medication Without Harm, WHO Global Patient Safety Challenge was published by the WHO in March 2017, to decrease patient harm which occurs due to unsafe medication practices and medication errors. The aim is to obtain worldwide commitment and action to decrease severe, preventable medication-related harm by $(50 \%)$ in the next 5 years specially by determining harm resulting from medication errors or unsafe procedures because of defects in healthcare systems (Donaldson et al., 2017).

In the present study, the participating physicians reported different types of errors they did, which differs according to the degree of each one. The most frequent error reported by specialists was unethical conduct in the form of deficient informed valid consent. Informed consent represented an important ethical issue before dealing with patients. Valid informed consent must be obtained from the patient before starting treatment or physical investigation for him as it is an essential ethical principle. The term informed consent in medicine defined as providing enough information for a patient to make an informed and rational choice. This principle reflects the right of patients to decide what occurs to their own (Heena et al., 2014).

While the residents mentioned that the most common error is diagnosis error. Binny et al. (2019), in their systemic review stated that, prescription errors were the most common errors mentioned.

Li et al. (2020), in their retrospective study of medical malpractice claim in China reported that of all (3175) medical error claims $(91.8 \%)$ were due to a medical technology error while $5.8 \%$ were medical ethics related errors, $0.9 \%$ were medical product errors and $1.6 \%$ were medical management errors.

The health care process in hospitals is very complicated and sensitive, so any minimal negligence in the physicians' duties can lead to defects.

In the current study, $76.3 \%$ of doctors reported they would conceal errors and $23.7 \%$ said they would disclose the occurred error. These results are in agreement with the results of Yassa and Peter (2018), who mentioned that $64.5 \%$ of doctors said they would conceal errors and $35.5 \%$ said they would disclose them. Those who choose to conceal, most of them (47\%) would do so due to fear of losing their reputation and legal consequences, and (17\%) due to fear of emotional impact of malpractice, and (10\%) fear of loss of doctorpatient relationship. Of those who choose to disclose errors, $(21 \%)$ stated that late disclosure destroys doctorpatient relationship, (18\%) said the patient has the right to know what happened, and (16\%) said that disclosure will increase patients' confidence in doctors. Error disclosure represents physicians' honesty and truthfulness, which can decrease patients discomfort, develop trust in physicians, and improve the patients emotional response; it also covered their need to be informed about the quality and manner of their care and increase awareness of their present condition, which will help the physicians to obtain informed consent for the management of damages resulted from the error and reduce in turn the compensation (Mohammad et al., 2019).

Also, Erik et al. (2014), stated that if an error occurs, disclosure is an essential step of the coping process for both patient and physician. Patients need to know what has happened because this will help them to take decisions about follow-up treatment. Also, 
disclosure is important to the physicians involved because they are the second victims of the errors. These incidents can produce negative emotional feedback up on the physicians. Additionally, disclosure can be considered an important part of strengthening the doctor- patient relationship. Alduais et al. (2014) stated that there are many barriers that prevent doctors from disclosure such as a lack of procedures for reporting errors to patients, fear of punishment, and lack of reporting. All of these can be avoided by improving the quality of doctors' training in how to report errors.

In the current study, doctors had the opinion that the hospital management system can decrease the risk of malpractice. Of the participants $42.7 \%$ said that performing risky procedures in qualified hospitals will prevent recurrence of errors and $41 \%$ will encourage doctors to disclose. While $16 \%$ stated that it is better to encourage hospitals to inform the agency by serious medical errors. For human factors, $51.3 \%$ said that refuse or referral of difficult case will save the patients and doctors, $34.3 \%$ need to give physician more time to spend with patients, $12.3 \%$ stated that increase number of nurses and assistant staff will decrease the occurrence of errors, only $2 \%$ said that counting surgical items used during invasive procedure will prevent recurrence of errors. These results differ from the results of Yassa and Peter (2018); in their study in Assiut Governorate, where doctors had the opinion that the hospital management system can reduce the risk of malpractice. As $39.1 \%$ of doctors said that the disclosure policies should be integrated into quality improvement programs, and $29.5 \%$ of them encouraged hospitals to report serious medical errors to the monitoring agency. The need for training on how to disclose reported by $20 \%$ of them and $11.4 \%$ advised that high risk procedures should take place in tertiary care hospitals.

Zamzam et al. (2019), stated many potential methods by health care providers that may help in decreasing $\mathrm{ME}$ incidents included the following as mentioned by the physicians; increasing awareness about medical responsibility; encouraging employees and auditors to report, perform regular assessment and evaluation, creation of a conducive working environment. Other suggestions were also reported including encourage communication between all departments, encourage reporting and discussing possible errors, development and preparation of new hospitals to decrease patient crowdedness per hospital.

\section{Conclusion}

The current study included 300 practicing physicians from Sohag Governorate. The main causes of medical errors reported by the participants were poor contact with patients and deficient skills. The participants' response was to avoid similar situations and increase information to prevent recurrence of error. The majority of participating doctors chose concealing the errors to avoid loss of reputation many preventive measures suggested by the participants to avoid recurrence of errors, the main measure was to perform risky procedures in well-equipped hospitals and referral of difficult cases to more qualified personnel and hospitals. This will save both doctors and patients.

\section{Recommendations}

- Close monitoring of residents and adequate communication between staff and regularization of duty hours should be applied which can decrease occurrence of errors.

- Legal protection for doctors and patients is mandatory as it can encourage doctors to disclose their errors.

- Finally, physicians should be aware toward medical errors as this will assist managers in planning to improve physicians' professional skills and maintain trust in the patient-physician relationship.

\section{References}

Alduais AM, Mogali S, Al Shabrain B, Al Enazi A and Alawad F (2014): Barriers and strategies of reporting medical errors in public hospitals in Riyadh city: A survey-study. J. Nurs. Health Sci., 3:72-85.

Ava M, Alireza A, Molouk H, Mohammadreza J, Seyed H K', Farzaneh D, Kheirollah G (2014): A review of medication errors in Iran: sources, underreporting reasons and preventive measures. Iran J. Pharm. Res., 13(1): 3-17

Bari A, Khan RA and Rathore AW (2016): Medical errors; causes, consequences, emotional response and resulting behavioral change. Pak. J. Med. Sci., 32(3): 523-528.

Binny T, Vibhu P, Katie M, Abdulrouf P, James M, Wessam Moza A and Derek S (2019): Medication errors in hospitals in the Middle East: a systematic review of prevalence, nature, severity and contributory factors. European Journal of Clinical Pharmacology, 75:1269-1282.

Brennan TA, Leape LL, Laird NM, Hebert L, Localio AR, Lawthers AG, Newhouse JP, Weiler PC, Hiatt HH (2004): Incidence of adverse events and negligence in hospitalized patients: results of the Harvard Medical Practice Study I. BMJ Qual. Saf., 13(2):145-151.

Donaldson LJ, Kelley ET, Dhingra-Kumar N, Kieny MP and Sheikh A (2017): Medication without harm: WHO's third global patient safety challenge. Lancet, 389:1680-1681.

Erik R, Manda H B and Kees A (2014): Explaining the unexplainable-the impact of physicians' attitude towards litigation on their incident disclosure behavior. Journal of Evaluation in Clinical Practice, 20: 649-656.

Gündo־gmus ÜN, Ersoy $\mathrm{N}$ and Biçer Ü. (1998): Analysis of the higher health council's decisions in respect of ethics. Toplum ve Hekim., 13:8-14.

Heena K, Ramandeep S G, Simarpreet S, Amarinder $\mathrm{K}$ and Tarun N (2014): Informed consent: Corner stone in ethical medical and dental Practice. J. Family Med. Prim. Care., 3(1): 6871.

Li H, Shengjie D, Ziyi L, Yao Y, Suwei Y, Yujie C, and Guohong L (2020): Retrospective analysis of 
medical malpractice claims in tertiary hospitals of China: the view from patient safety. BMJ., 10: e034681.

Martin-Casals M, Igualada JL, and Feliu JS (2003): Medical malpractice liability in Spain: cases, trends and developments. European Journal of Health Law, 1:153-181.

Mohammad M, Bagher L, Seyed MT, Saharnaz N, Masud Y, and Fatemeh S N (2019): A study of validity and reliability of the questioner entitled physicians approach to and disclosure of medical errors and the related ethical issues. Medical Ethics and History of Medicine Research Center, 12(2):1-15.

Nakajima K, Keyes C, Kuroyanagi $\mathrm{T}$ and Tatara K (2001): Medical malpractice and legal resolution system in Japan. JAMA., 285:16321640.

Tully MP, Ashcroft DM, Dornan T, Lewis PJ, Taylor D and Wass V (2009): The causes of and factors associated with prescribing errors in hospital inpatients. Drug Saf., 32(10):819-836.

Wakefield BJ, Wakefield, DS, and Uden-Holman, T (2000): Improving medication administration error reporting systems. Why do errors occur? Ambulance Outreach: 16-20

West CP, Tan AD, Habermann TM, Sloan JA and Shanafelt TD (2009): Association of resident fatigue and distress with perceived medical errors. Jama., 302(12):1294- 1300.

Yassa HA and Peter A F (2018): Medical error disclosure can rescue malpractice litigation. Arab Journal of Forensic Sciences \& Forensic Medicine; 1 (7): 859-868.

Zamzam A, Mohammad S, Alan MJ, Abdullah MA (2019): Medical errors: Healthcare professionals' perspective at a tertiary hospital in Kuwait. PLOS ONE: 1-14.

\section{هل من الافضل الافصاح ام اخفاء الخطأ الطبي اذا حدث؟ دراسة استرشادية من أطباء محافظة سوهاج}

$$
\text { رضا محمد السيد' و نسرين علي محمد' و رانيا احمد رضوان' }
$$

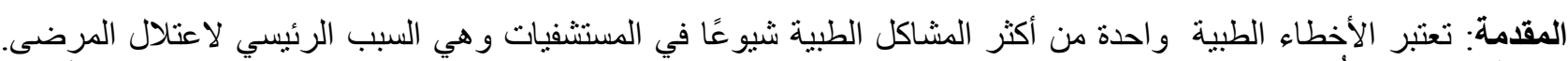

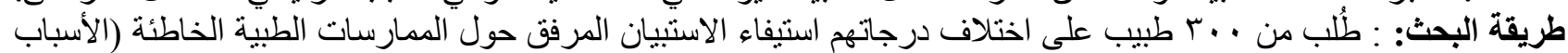

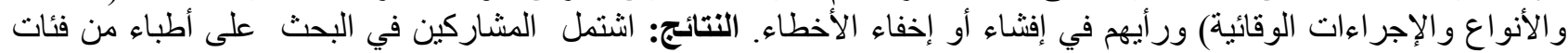

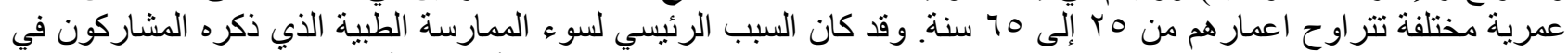

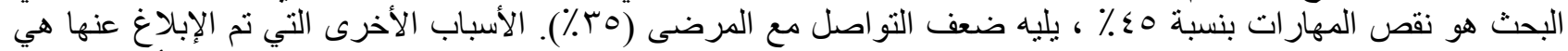

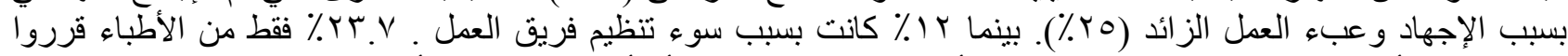

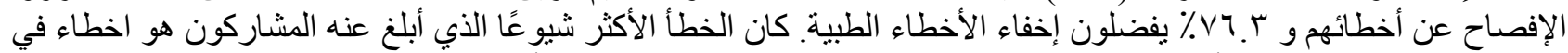

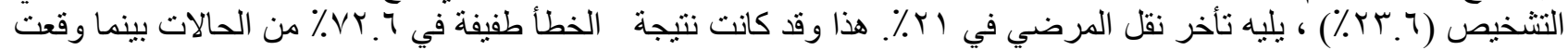

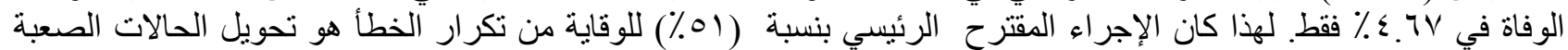

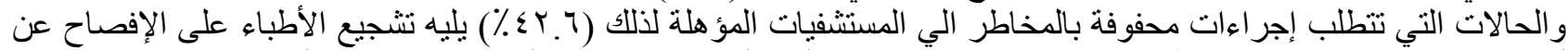

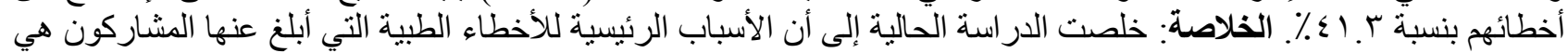

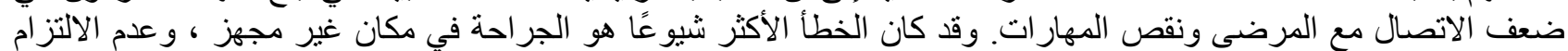

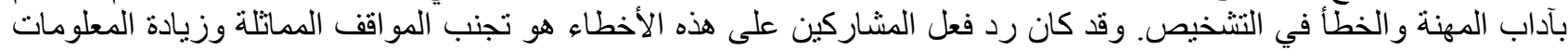

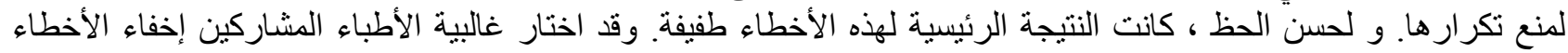

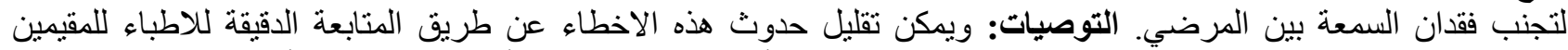

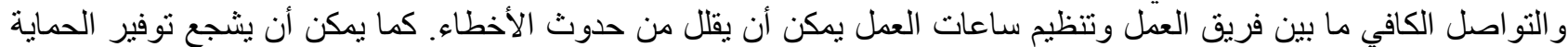
القانونية للأطباء و المرضى الأطباء على الكثف عن عن أخطائهر. 